\title{
Photosensitive Posthypoxic Reflex Myoclonus in a Postcardiac Arrest Individual: An Interesting Finding
}

Sir,

Patients who survive a cardiac arrest are increasing because of recent development of medical technologies in prompt resuscitation and restoration of cardiopulmonary status. As a result, such individuals tend to have diverse and severe neurological sequelae. These include dyskinesia due to hypoxic brain damage, and their disorders include parkinsonism, dystonia, chorea, athetosis, tremor, and myoclonus. ${ }^{[1]}$ Posthypoxic myoclonus (PHM) refers to myoclonus that occurs after hypoxic brain damage due to cardiac arrest. ${ }^{[2]}$ According to its onset, PHM can be divided into two types, acute and chronic. Acute PHM is the occurrence of myoclonus within $48 \mathrm{~h}$ after a cardiac arrest and usually present as myoclonic status epilepticus. ${ }^{[3]}$ Area-specific, stimulus-sensitive postanoxic myoclonus is very rare. We report a patient who had stimulus-sensitive myoclonus involving the face and right upper limb only to light stimulus over the face within $24 \mathrm{~h}$ following cardiac arrest.

A 36-year-old male was brought to emergency room with a history of unresponsiveness of $2 \mathrm{~h}$ duration during early morning. The patient was apparently asymptomatic the previous night. There was no witnessed history of seizures or head injury and no previous known comorbidities. On examination, vitals were normal. The patient was irritable and restless with Glasgow coma scale (GCS) of 8/15 $\left(\mathrm{E}_{2} \mathrm{M}_{4} \mathrm{~V}_{2}\right)$. He had left upper motor neuron facial palsy with paucity of movements in left upper and lower limb. His left plantar was extensor in response. Arterial glucose level was $118 \mathrm{mg} / \mathrm{dL}$ and arterial blood gas was normal. Complete hemogram and renal and hepatic function tests were within normal limits. Cranial computed tomography imaging revealed acute middle cerebral artery territory infarct. He was admitted to Neuro-Intensive Care Unit (ICU) and was started on heparin, antiplatelet with anti-edema measures. During the ICU stay, he suffered a cardiac arrest, and cardiopulmonary resuscitation (CPR) was performed for about $10 \mathrm{~min}$. He was revived and his vital signs returned to normal. On postcardiac arrest state, he was deeply comatose with GCS score of 3/15 $\left(E_{1} M_{1} V_{T}\right)$. Within few hours, he developed episodic, jerky movement of face and right upper limb only on shining the light over the face and used to persist till the light stimulus is on the face. This was noticed by nursing staff while they used to shine light over the eyes to note pupillary reaction. These movements were absent on acoustic stimulus. These involuntary movements were suggestive of myoclonus which was stimulus sensitive to light only [Video 1]. The movements were not elicited on acoustic stimulus. There were no generalized tonic-clonic seizures or spontaneous myoclonus. The patient succumbed to death within $12 \mathrm{~h}$. Electroencephalogram (EEG) revealed diffuse slowing of background rhythm.

Acute PHM occurs in about $19 \%-37 \%$ of patients who suffered hypoxic brain damage due to cardiac arrest. These typically occur within the first $24 \mathrm{~h}$ after CPR. ${ }^{[4]}$ They can be divided into status myoclonus and focal myoclonus. Status myoclonus refers to spontaneous or sound-sensitive, repetitive, irregular brief jerks in both face and limb present during most of the $1^{\text {st }}$ day after CPR. ${ }^{[4]}$ There are no specific EEG criteria that have been described. Focal myoclonus after CPR has also been reported. The exact pathophysiology of acute PHM is poorly understood. ${ }^{[5]}$ They usually originate from subcortical and/or cortical structures. ${ }^{[1]}$ Histological studies have revealed significantly more neuronal loss in all cortical laminae in patients with myoclonus. Cortical myoclonus is primarily treated with levetiracetam or piracetam whereas subcortical myoclonus is usually treated with clonazepam. ${ }^{[6]}$ The majority of studies on acute PHM were performed before introduction of hypothermia as a treatment option after CPR was implemented. With the increasing usage of hypothermia and administration of neuromuscular blocking agents in the management of hypoxic brain damage, the appearance of acute PHM is suppressed during the $1^{\text {st }}$ day after the admission. There are no evidence-based guidelines for treatment of acute PHM. Cortically generated myoclonus is mainly focal or multifocal and affects body parts with a large cortical representation, such as hand and face. Subcortical myoclonus on the other hand, especially reticular myoclonus, is generalized, predominantly affecting axial and proximal limbs. ${ }^{[7]}$ Stimulus sensitivity occurs in both types of myoclonus. In cortical myoclonus, giant potentials are seen on somatosensory-evoked potential (SEP) recordings and epileptiform discharges in the EEG. SEP is normal with no consistent abnormalities in the EEG in subcortical myoclonus. ${ }^{[8]}$ Our patient had most probably cortical myoclonus as it involved the face and upper limb which has largest cortical representation. It was stimulus sensitive to light only. Somatosensory recording was not feasible as he was 
on mechanical ventilator. EEG showed diffuse slowing of background rhythm. Acute PHM carries a poorer prognosis with survival rates of $0 \%-11 \%$. Niedermeyer et al. reported a patient who had acute cerebral anoxia and developed myoclonic jerks which could be elicited on light touch of the right trigeminal area (but of no other body region). ${ }^{[9]}$ Our patient had similar myoclonic jerks elicited on light stimulus of the right trigeminal area (but of no other body region). Zivkovic and Brenner reported a patient with cardiorespiratory arrest who had generalized myoclonic jerks on periorbital stimulation (trigeminal-innervated areas) with resting EEG electrocerebral silence. ${ }^{[10]}$

Acute PHM is usually spontaneous or sound-sensitive and occurs within $24 \mathrm{~h}$ following hypoxic damage to brain. It carries a poor prognosis. Area-specific, stimulus-sensitive postanoxic myoclonus is very rare. This case demonstrates the rare occurrence of acute PHM sensitive to light stimulus only with no spontaneous or sound-sensitive myoclonus as described in literature.

\section{Financial support and sponsorship}

Nil.

\section{Conflicts of interest}

There are no conflicts of interest.

Rohan R. Mahale, Anish Mehta, R. Srinivasa

Department of Neurology, M. S. Ramaiah Medical College and Hospital, Bengaluru, Karnataka, India

Address for correspondence: Dr. Rohan R. Mahale, Department of Neurology, M. S. Ramaiah Medical College and Hospital, Bengaluru - 560 054, Karnataka, India. E-mail: rohanmahale83@gmail.com

\section{REFERENCES}

1. Venkatesan A, Frucht S. Movement disorders after resuscitation from cardiac arrest. Neurol Clin 2006;24:123-32.

2. Choi HC, Song HK. Is the intensive anticonvulsant treatment for control of acute posthypoxic myoclonic status epilepticus necessary? J Korean Neurol Assoc 2006;24:125-30.

3. Thömke F, Marx JJ, Sauer O, Hundsberger T, Hägele S, Wiechelt $\mathrm{J}$, et al. Observations on comatose survivors of cardiopulmonary resuscitation with generalized myoclonus. BMC Neurol 2005;5:14.

4. Wijdicks EF, Parisi JE, Sharbrough FW. Prognostic value of myoclonus status in comatose survivors of cardiac arrest. Ann Neurol 1994;35:239-43.

5. Young GB, Gilbert JJ, Zochodne DW. The significance of myoclonic status epilepticus in postanoxic coma. Neurology 1990;40:1843-8.

6. Frucht S, Fahn S. The clinical spectrum of posthypoxic myoclonus. Mov Disord 2000;15 Suppl 1:2-7.

7. Caviness JN, Brown P. Myoclonus: Current concepts and recent advances. Lancet Neurol 2004;3:598-607.

8. Cassim F, Houdayer E. Neurophysiology of myoclonus. Neurophysiol Clin 2006;36:281-91.

9. Niedermeyer E, Bauer G, Burnite R, Reichenbach D. Selective stimulus-sensitive myoclonus in acute cerebral anoxia. A case report. Arch Neurol 1977;34:365-8.

10. Zivkovic SA, Brenner RP. A case of area-specific stimulus-sensitive postanoxic myoclonus. J Clin Neurophysiol 2003;20:111-6.

This is an open access article distributed under the terms of the Creative Commons Attribution-NonCommercial-ShareAlike 3.0 License, which allows others to remix, tweak, and build upon the work non-commercially, as long as the author is credited and the new creations are licensed under the identical terms.

Video available on: www.ruralneuropractice.com

\begin{tabular}{|l|l|}
\hline \multicolumn{2}{|c|}{ Video available on: www.ruralneuropractice.com } \\
\hline \multicolumn{2}{|c|}{ Access this article online } \\
\hline Quick Response Code: & Website: \\
\hline
\end{tabular}

How to cite this article: Mahale RR, Mehta A, Srinivasa R. Photosensitive posthypoxic reflex myoclonus in a postcardiac arrest individual: An interesting finding. J Neurosci Rural Pract 2017;8:489-90.

(C) 2017 Journal of Neurosciences in Rural Practice | Published by Wolters Kluwer - Medknow 